\title{
Parathyroid adenoma presenting with multiple Brown tumors in an adolescent patient
}

\author{
(D) Serdar Aslan, ${ }^{1}$ (1) Meltem Ceyhan Bilgici, ${ }^{1}$ (i) Riza Ferit Bernay, ${ }^{2}$ \\ (D) Hasan Murat Aydin, ${ }^{3}$ (D) Mustafa Bekir Selcuk ${ }^{1}$ \\ ${ }^{1}$ Department of Radiology, Ondokuz Mayis University Faculty of Medicine, Samsun, Turkey \\ 2Department of Pediatric Surgery, Ondokuz Mayis University Faculty of Medicine, Samsun, Turkey \\ ${ }^{3}$ Department of Pediatrics, Ondokuz Mayis University Faculty of Medicine, Samsun, Turkey
}

\begin{abstract}
Parathyroid glands are endocrine glands that secrete parathyroid hormone (PTH) and regulate calcium-phosphor metabolism. The overexpression of PTH is called hyperparathyroidism (HPT), and is classified as primary, secondary, and tertiary. Primer HPT (PHPT) is the most common cause of parathyroid adenomas (80\%-85\%). Development of juvenile PHPT during adolescence is rare. The incidence of bone lesions in all age groups is reported to be $10 \%-20 \%$ in the patients with PHPT, and $5 \%$ in patients with juvenile PHPT. In patients with bone lesions, regression occurs in lesions after parathyroidectomy. In this case report, we aimed to present the imaging findings of long bones and left fifth metacarpal bone multiple Brown tumors, which is a rare presentation of parathyroid adenoma in adolescent patient and regression after parathyroidectomy.
\end{abstract}

Keywords: Adolescent; Brown tumor; primary hyperparathyroidism.

Cite this article as: Aslan S, Ceyhan Bilgici M, Bernay RF, Aydin HM, Selcuk MB. Parathyroid adenoma presenting with multiple Brown tumors in an adolescent patient. North Clin Istanb 2018;5(4):361-364.

$\mathrm{P}$ arathyroid glands are two endocrine glands, which are usually located in vicinity of the upper and lower poles of the thyroid gland. Parathyroid glands secrete parathormone (PTH) and regulate calcium-phosphorus metabolism. PTH plays an important role in bone mineral balance. The overexpression of PTH is termed as hyperparathyroidism (HPT), and it is classified as primary, secondary, and tertiary hyperparathyroidism.

Primary HPT (PHPT) develops as a result of adenoma $(80 \%-85 \%)$, hyperplasia (10\%-15\%), and parathyroid carcinoma $(<0.5 \%)$ [1]. Secondary HPT develops due to overexpression of PTH secondary to hypocalcemia or vitamin D deficiency. Tertiary HPT develops as a result of autonomy acquired by the parathyroid glands as a result of long-lasting secondary HPT [2]. Juvenile PHPT in the adolescent period is very rare, and only a limited number of cases have been reported in the literature [3].
The incidence of bone lesions in PHPT was reported to be $10 \%-20 \%$, and in juvenile PHPT as $5 \%$ [4]. The most commonly identified bone lesions are bone resorption, bone cysts, Brown tumors, and generalized osteopenia. Bone lesions are often seen in facial bones, ribs, and pelvic bones. They are rarely seen in long bones. Brown tumors are reactive lesions that result in disruption of the balance between bone formation and destruction in favor of bone resorption due to the direct effect of PHT. Diagnosis is difficult, and is radiologically confused with giant cell tumor, bone metastasis, or multiple myeloma [5].

In this case report, we aimed to present the imaging findings of a large number of Brown tumors in the long bones and the fifth metacarp of the left hand, which have a rare manifestation of parathyroid adenoma in the adolescent patient that regresses after parathyroidectomy.

Received: October 08, 2017 Accepted: January 02, 2017 Online: August 09, 2018

Correspondence: Dr. Serdar ASLAN. Ondokuz Mayis Universitesi Tip Fakultesi, Radyoloji Anabilim Dali, 55139 Samsun, Turkey.

Phone: +90 5448852276 e-mail: serdaraslan28@hotmail.com

(c) Copyright 2018 by Istanbul Provincial Directorate of Health - Available online at www.northclinist.com 


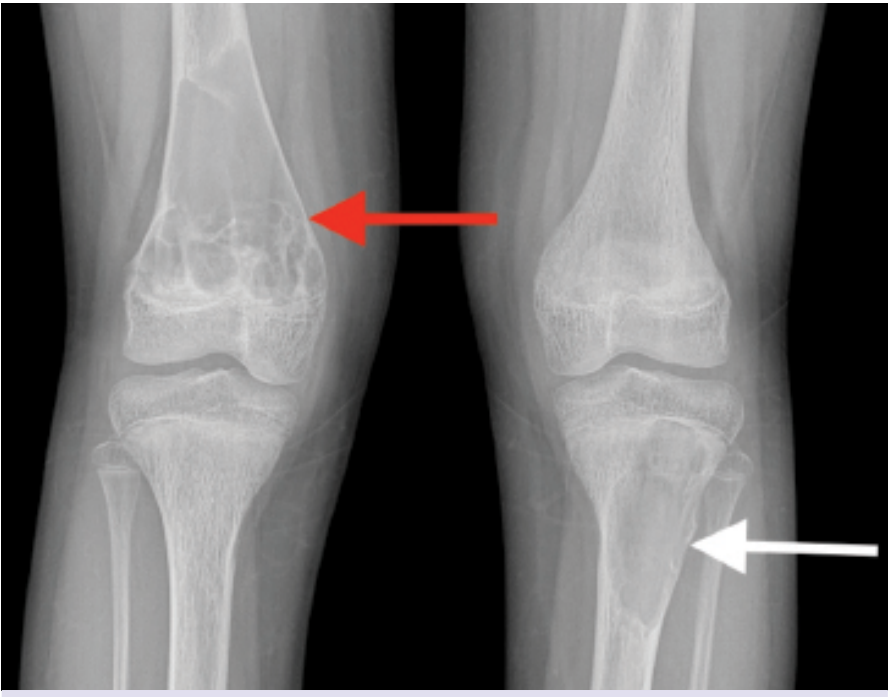

FIGURE 1. A bone lesion measuring $71 \times 30 \mathrm{~mm}$ (white arrow) on the proximal metaphysis of the left tibia and the other one measuring $87 \times 44 \mathrm{~mm}$ in size (red arrow) in the distal metaphysis of the right femur are observed.

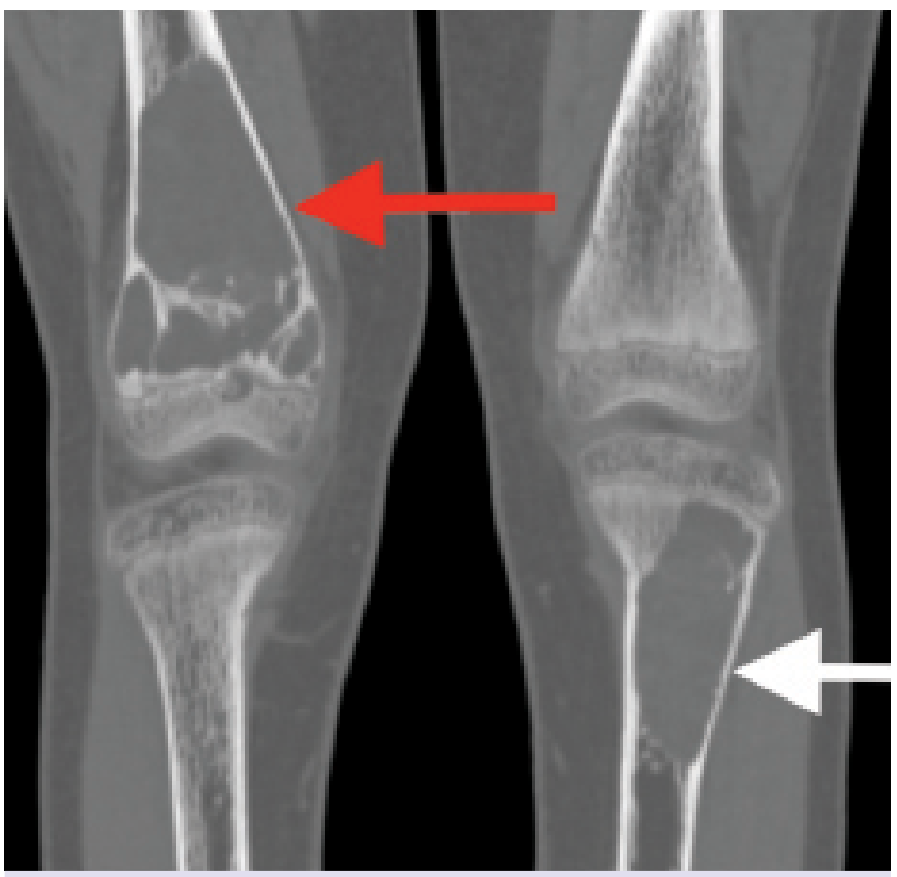

FIGURE 2. A bone lesion measuring $66 \times 30 \mathrm{~mm}$ (white arrow) in the proximal metaphysis of the left tibia and the other one measuring $80 \times 36 \mathrm{~mm}$ in the distal metaphysis of the right femur (red arrow) are observed.

\section{CASE REPORT}

A 14-year-old girl was admitted to the outpatient orthopedic clinic with complaints of increasing pain and

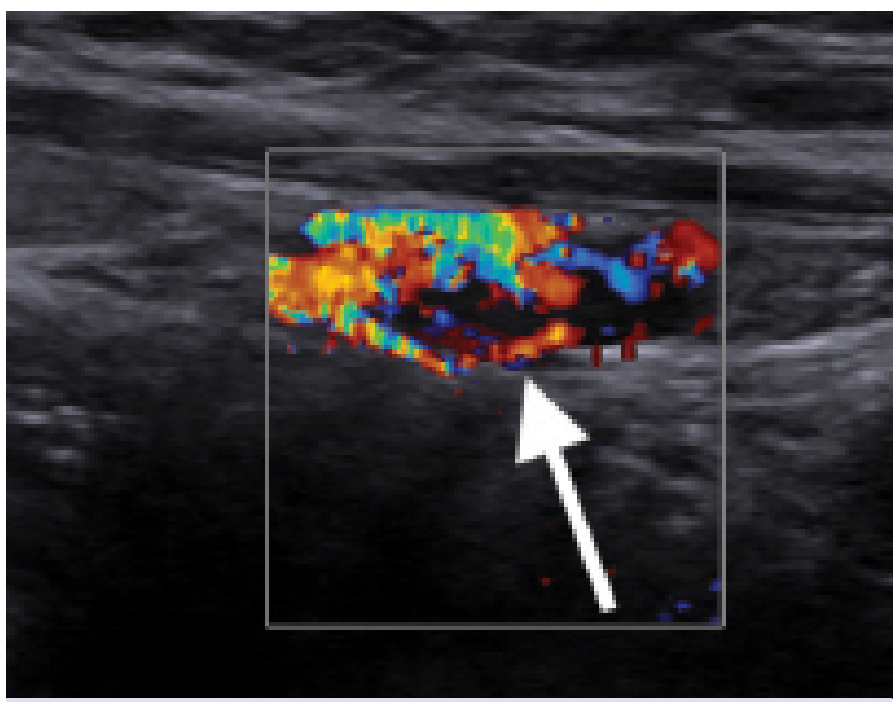

FIGURE 3. Parathyroid adenoma-compatible lesion (white arrow) in the size of $11,5 \times 5,5 \times 19,5 \mathrm{~mm}$ is seen in the inferior lobe of the left thyroid gland.

fatigue on her left knee for one month. On physical examination, the patient's weight $(40 \mathrm{~kg}(<3 \mathrm{p})$ and height $146 \mathrm{~cm}(<3 p)$ were measured. Her left knee movements were minimally limited. Bilateral knee Xray and lower extremity long bone radiograms were obtained, and the patient was referred to us. Radiograms revealed radiolucent bone lesions proximal to the left tibia and distal to the right femur and extensive decrease in bone densities (Fig. 1). Other bones were scanned to detect the presence of bone lesion. A bone lesion with similar appearance was observed in distal part of the fifth metacarp of the left hand. Lowdose computed tomography (CT) of both lower extremities was performed to aid in differential diagnosis. Likewise, CT demonstrated expansile, hypodense bone lesions at a location proximal to the left tibia and distal to the right femur (Fig. 2, remarkable laboratory findings were as follows: calcium, $13.4 \mathrm{mg} / \mathrm{dL}(8.6-10$ $\mathrm{mg} / \mathrm{dL})$; phosphorus, $2.22 \mathrm{mg} / \mathrm{dL}(2.6-4 \mathrm{mg} / \mathrm{dL})$; alkaline phosphatase $636 \mathrm{IU} / \mathrm{L}(73-189 \mathrm{IU} / \mathrm{L}) ; 25-\mathrm{OH}$ Vitamin D3 $1.25 \mu \mathrm{g} / \mathrm{L}(10-55 \mu \mathrm{g} / \mathrm{L})$, and PTH 1441 $\mathrm{pg} / \mathrm{mL}(10-65 \mathrm{pg} / \mathrm{mL})$.

With available findings, lesions were thought to be Brown tumors due to PHPT. Neck ultrasonography (USG) and parathyroid scintigraphy ( $\mathrm{Tc}^{99 \mathrm{~m}}$ sestamibi) were performed to investigate the etiology. In the neck US, a lesion compatible with parathyroid adenoma was observed near the lower left thyroid gland (Fig. 3). Sintigraphy also showed findings consistent with parathyroid 


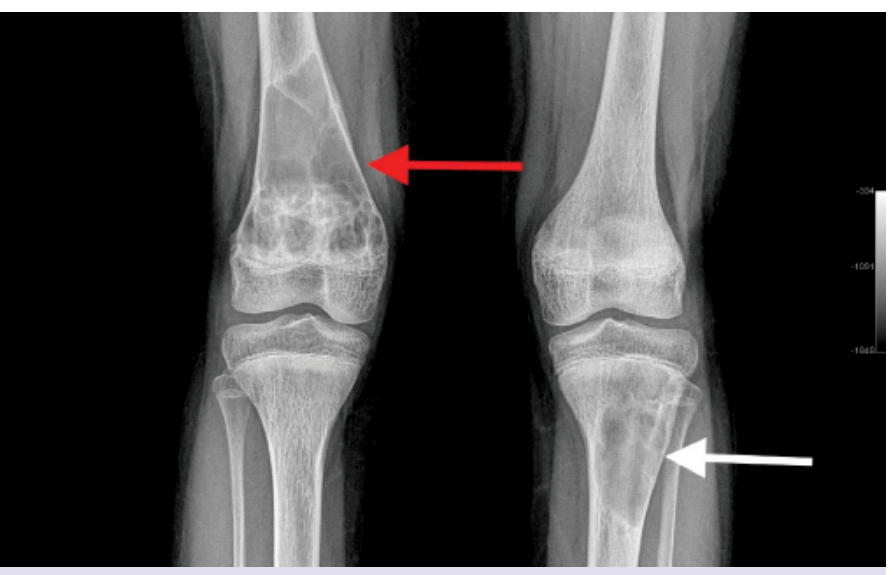

FIGURE 4. Decreases in the dimensions of the Brown tumors localized in the tibia and femur are observed on the control knee radiograms.

adenoma. The patient was diagnosed with parathyroid adenoma and Brown tumor developed secondary to parathyroid adenoma.

Parathyroid adenoma was removed by the department of surgery. The calcium and PTH levels were normal after parathyroidectomy. The patient had no complaints at 1-month follow-up; and the calcium, PTH, and phosphorus levels were normal. The size of the lesions seen in the knee radiogram also decreased (Fig. 4). Thus, without the need for biopsy, it was proved that the lesions were Brown tumor, and they developed due to parathyroid adenoma.

\section{DISCUSSION}

We presented an adolescent patient who presented with left knee pain, and had multiple Brown tumors in the long bones of the lower extremities. Radiographically detected bone lesions and laboratory findings supporting PHPT primarily suggested us the presence of Brown tumor. Normalization of PTH after parathyroidectomy and decrease in the size of the lesions in the control imaging performed one month later confirmed our diagnosis without the necessity of biopsy or surgical intervention.

The Brown tumor is a slowly growing, occasionally painful, and locally aggressive bone lesion without metastatic potential. The incidence of Brown tumor in PHPT is reported to range between $1.5 \%$ and $1.7 \%$ [6]. It is frequently seen in adults over the age of 50 years, but the appearance of Brown tumors secondary to parathy- roid adenoma in the adolescence period is very rare [7]. The imaging findings of the Brown tumor are not specific. They are frequently seen as bone lesions with lytic or sclerotic contours that do not cause cortical erosion, inflammatory changes, or periosteal reaction [8]. They are rarely localized in long bones, and they are seldom seen in multiple numbers. It may be confused with giant cell tumor, aneurysmal bone cyst, giant cell granuloma, or cherubism when it develops in the mandible, and it may be confused also with metastasis when it is seen in multiple numbers [6].

In the literature, most of the cases of the Brown tumor have been presented in a single bone and mostly in the mandibula and palate [9]. It is difficult to make the diagnosis of Brown tumor in biopsy materials histopathologically, and diagnosis can be frequent indicated if clinical manifestations of HPT are found.

In cases of suspect Brown tumor, the presence of parathyroid adenoma should be investigated before resorting to biopsy and surgical intervention.

If parathyroid adenoma is detected, parathyroidectomy is the most appropriate option. With parathyroidectomy, the PTH levels are kept under control, and also existing Brown tumors are treated $[4,10]$. Tumors that grow despite treatment or do not change in size during the 6-month period after treatment, and lesions that impair the functions of the affected bone, or those associated with fractures require interventional treatment [10].

In conclusion, Brown tumor is a rare bone lesion that develops secondary to PHPT in adolescents, and it can be anticipated in cases with prolonged PHT elevation. Imaging methods are important diagnostic tools. When suspect lesions are revealed by imaging modalities, the patients should not be immediately directed to biopsy, differential diagnosis should be considered, biochemical values should be reviewed, and the presence of parathyroid adenoma should be investigated.

Informed Consent: Written informed consent was obtained from the patient for the publication of the case report and the accompanying images.

Conflict of Interest: No conflict of interest was declared by the authors.

Financial Disclosure: The authors declared that this study has received no financial support.

Authorship Contributions: Concept - S.A.; Design - S.A.; Supervision - S.A.; Materials - S.A.; Data collection \&/or processing - M.C.B., R.F.B., H.M.A., M.B.S.; Analysis and/or interpretation M.C.B., R.F.B., H.M.A., M.B.S.; Writing - S.A.; Critical review - S.A. 


\section{REFERENCES}

1. Kanaan I, Ahmed M, Rifai A, Alwatban J. Sphenoid sinus brown tumor of secondary hyperparathyroidism: case report. Neurosurgery 1998;42:1374-7. [CrossRef]

2. Som PM, Lawson W, Cohen BA. Giant-cell lesions of the facial bones. Radiology 1983;147:129-34. [CrossRef]

3. Monneuse O, Causeret S, Lifante JC, Berger N, Lapras V, Peix JL. Primary juvenile hyperparathyroidism. Report of 24 cases. Ann Chir 2002;127:276-80. [CrossRef]

4. Yamazaki H, Ota Y, Aoki T, Karakida K. Brown tumor of the maxilla and mandible: progressive mandibular brown tumor after removal of parathyroid adenoma. J Oral Maxillofac Surg 2003;61:719-22.

5. Ahmad R, Hammond JM. Primary, secondary, and tertiary hyperparathyroidism. Otolaryngol Clin North Am 2004;37:701-13.
6. Atabek ME, Pirgon O, Sert A, Esen HH. Extensive brown tumors caused by parathyroid adenoma in an adolescent patient. Eur J Pediatr 2008;167:117-9. [CrossRef]

7. Hoshi M, Takami M, Kajikawa M, Teramura K, Okamoto T, Yanagida I, et al. A case of multiple skeletal lesions of brown tumors, mimicking carcinoma metastases. Arch Orthop Trauma Surg 2008;128:149-54.

8. Daniels JS. Primary hyperparathyroidism presenting as a palatal brown tumor. Oral Surg Oral Med Oral Pathol Oral Radiol Endod 2004;98:409-13. [CrossRef]

9. Cupisti K, Raffel A, Dotzenrath C, Krausch M, Röher HD, Schulte KM. Primary hyperparathyroidism in the young age group: particularities of diagnostic and therapeutic schemes. World J Surg 2004;28:1153-6. [CrossRef]

10. Pallan S, Rahman MO, Khan AA. Diagnosis and management of primary hyperparathyroidism. BMJ 2012;344:e1013. [CrossRef] 